\title{
Evaluation of risk factors causing osteoporosis in chronic obstructive pulmonary disease (COPD) Patients.
}

\author{
Aiman Saeed ${ }^{1}$, Humaira Parveen ${ }^{2}$, Bushra Jamil ${ }^{3}$ \\ 1,2,3. House Officer Nishtar Hospital, Multan \\ Corresponding Author: bushrajamil14@yahoo.com
}

Abstract

Objective: The main aim of study was to investigate the prevalence of risk factors and osteoporosis in chronic obstructive pulmonary disease patients.

Methods: This prospective cross sectional study was done in pulmonology department Nishtar Hospital Multan. Total 369 patients of chronic obstructive pulmonary disease, diagnosed according to Global Initiative for Chronic Obstructive Lung Diseases (GOLD) criteria were enrolled by non-probability consecutive sampling. The study was conducted from January 2016 to November 2016. Ethical approval was taken from committee of the hospital. Written permission was signed by each patient included in study. Quantitative variables like age, body mass index, FEV1, pack years smoking and vitamin D were statistically measured in mean and standard deviation. Qualitative variables like gender and area of living were statistically analyzed in percentage and frequency. ANNOVA was applied to test the significance. P value $<0.05$ was taken as significant.

Results: Overall, 100\% ( $\mathrm{n}=369)$ patients were included, in this study; divided into two groups i.e. nonosteoporosis $60 \%(n=220)$ and osteoporosis $40 \%(n=149)$. The mean age, BMI and smoking pack-years of the non-osteoporosis patients was $67.99 \pm 4.61$ years, $23.92 \pm 1.95 \mathrm{~kg} / \mathrm{m}^{2}$ and $41.62 \pm 10.20$ respectively. There were 94.1\% $(n=207)$ males and 5.9\% $(n=13)$ females. While, the mean age, BMI and smoking pack-years of the osteoporosis patients was $71.44 \pm 3.90$ years, $21.91 \pm 3.26 \mathrm{~kg} / \mathrm{m}^{2}$ and $49.05 \pm 3.00$ respectively. There were $97.3 \%$ $(\mathrm{n}=145)$ males and $2.7 \%(\mathrm{n}=4)$ females. Education status of the non-osteoporosis patients observed as $36.4 \%$ $(\mathrm{n}=80)$ illiterate and $63.6 \%(\mathrm{n}=140)$ elementary or above, while there were $38.3 \%(\mathrm{n}=57)$ osteoporosis patients illiterate and $61.7 \%(\mathrm{n}=92)$ were elementary or above. Significant differences were found between age $(\mathrm{p}=0.000)$, BMI $(\mathrm{p}=0.000)$, smoking pack years $(\mathrm{p}=0.000)$, BMD T-score $(\mathrm{p}=0.000)$, Systolic BP $(\mathrm{p}=0.000)$, Diastolic BP $(p=0.000), F V C$, liters $(p=0.000), F V C$, predicted $\%,(p=0.000), F E V 1$, liters $(p=0.000), F E V 1$, predicted $\%(p=0.000)$ and FEV1/FVC $(p=0.000)$, in groups. Association was found between HTN $(p=0.000)$ and $\operatorname{GOLD}(\mathrm{p}=0.001)$ in groups.

Conclusion: Study concluded that osteoporosis is hidden and common comorbidity in chronic obstructive pulmonary disease patients. Its prevalence was high among the patients. ------ were independent risk factors in developing osteoporosis in chronic obstructive pulmonary disease patients. Pulmonologists should consider and properly investigate osteoporosis in chronic obstructive pulmonary disease patients.

Key words: Chronic obstructive pulmonary disease, osteoporosis, bone mineral density

DOI: $10.7176 / \mathrm{JMPB} / 54-06$

Publication date: April $30^{\text {th }} 2019$

Introduction

Chronic obstructive pulmonary disease (COPD) is very common respiratory problem. It is a chronic inflammatory disease of lung $\{1\}$. Systemic chronic inflammation is caused by TNF-alpha, IL-6, CRP and IL-8 $\{2\}$. It greatly affects the quality of life $\{3\}$. Chronic obstructive pulmonary disease is characterized by persistent and irreversible air flow limitation $\{4\}$. Chronic obstructive pulmonary disease is treatable and progressive disease. Chronic obstructive disease occurs in adults and older age patients. Patients of chronic obstructive disease clinically present with symptoms of cough, chest pain, dyspnea and sputum mostly. It is cause of great burden on health care system. Chronic obstructive disease is one of the leading cause of mortality. It is expected to be the third most common cause of mortality in $2020\{5\}$. Many complications occur in chronic obstructive pulmonary disease patients like anemia, muscle wasting, cachexia and weight loss. Most cases of chronic obstructive pulmonary disease occur due to smoking $\{6\}$. Other factors such as bio mass fuel exposure $\{7\}$, environmental pollution, toxic agents on work place can cause chronic obstructive pulmonary disease. Inflammation to these hazardous agents in airways result in bronchospasm and mucous glands hyperplasia. Chronic obstructive pulmonary disease patients usually have many comorbidities like diabetes, hypertension and cardiovascular disease. Erectile dysfunction is also common problem in chronic obstructive pulmonary disease 
patients $\{8\}$. Acute exacerbation of chronic obstructive pulmonary disease is crucial event in the course of disease. It is main reason of hospitalization in chronic obstructive pulmonary disease patients. It is estimated that $50-70 \%$ cost associated with chronic obstructive pulmonary disease is due to its exacerbation.

Osteoporosis is bone disorder which is caused by change in micro architectural of the skeleton due to low bone mineral density (BMD) $\{9\}$. Bone strength and quality mainly depends on the three dimensional micro architectural of bone and also properties of material constituents. Type 1 collagen and hydroxyapatite crystals are the main constituents of bone $\{10\}$. Osteoporosis increase the chances of fracture by compromising the bone strength. There is no clinical tool to evaluate the quality of bone. However, bone mineral density is measured by dual-energy X-ray absorptiometry (DXA). According to WHO criteria osteoporosis is diagnosed when bone mineral density is 2.5 standard deviation or more to young adult mean. Bone mineral density reflects nearly $70 \%$ strength of bone.

It has been investigated that there is a strong association of osteoporosis in COPD patients. The development of osteoporosis in chronic obstructive pulmonary disease patients is caused by many risk factors. Age, smoking, low body mass index, use of steroid, low levels of vitamin $\mathrm{D}$, decrease physical activity and chronic inflammation are the common factors that result in osteoporosis in chronic obstructive pulmonary disease patients. Osteoporosis has its complications in chronic obstructive pulmonary disease patients. It increases the chances of osteoporotic fractures and affects the quality of life $\{11\}$.

Rationale of the study was that osteoporosis is common and hidden comorbidity in chronic obstructive pulmonary disease patients. It is extremely under investigated and undertreated condition in chronic obstructive pulmonary disease. Currently, very limited research had been conducted on prevalence and risk factors of osteoporosis in chronic obstructive pulmonary disease in Pakistan. So this study will help to establish the facts and also provide base for further investigation. Study done by Chun-Wei lin et al. in Taiwan was taken as reference study $\{12\}$.

\section{Materials and methods}

This prospective cross sectional study was done in pulmonology department Nishtar Hospital Multan. Total 369 patients of chronic obstructive pulmonary disease, diagnosed according to Global Initiative for Chronic Obstructive Lung Diseases (GOLD) criteria were enrolled by non-probability consecutive sampling. The study was conducted from January 2016 to November 2016. Ethical approval was taken from committee of the hospital. Written permission was signed by each patient included in study. All patients having clinically stable chronic obstructive pulmonary disease disease and can perform mild physical activity were included in study. Exclusion criteria of study were: 1) patients who were using systemic corticosteroids, 2) patients having history of any malignancy, 3) any history of acute exacerbation of chronic obstructive pulmonary disease in last one year, 4) patients having history of other systemic diseases like endocrine, renal, gastrointestinal, cardiovascular and rheumatology which can effect bone mineralization and patients having other than chronic obstructive pulmonary disease respiratory disorder were excluded from the study. Sample size was collected from a reference study done by Chun Wei Lin et al. for which confidence interval was taken as $95 \%$, study strength 80 , $40 \%$ of chronic obstructive pulmonary disease patients having osteoporosis $\{12\}$.

All patients were recruited from outpatient department. A detailed history of disease, smoking habits, history of pain and physical activity were taken. Complete physical examination was done in every patient to assess the severity of disease, its complications and any clue of other systemic disorder. Personal information of each patient like age, gender, body mass index, area of living and smoking status was recorded by filling the Performa. On the investigation day pulmonary function tests, bone mineral density and fasting blood glucose were recorded.

Spirometry was done to check the pulmonary functions. It was done by same technician in each patient and in sitting position. Three technically correct values of FEV1, FVC and FEC1/FVC were recorded and highest of three value was taken in study.

Bone mineral density was checked by using dual energy X ray absorptiometry (DEXA). Left hip joint, anterior posterior lumbar spine (L1 to L4) and total bone mineral density were measured individually in absolute values in grams of minerals per unit area scanned $(\mathrm{g} / \mathrm{cm})$ and relative T-scores. According to WHO criteria osteoporosis is diagnosed when bone mineral density is 2.5 standard deviation or more to young adult mean 
In all patient's venous sample was drawn between 6 a.m. to 9 a.m. Complete blood analysis and fasting blood sugar levels were measured

Quantitative variables like age, body mass index, FEV1, pack years smoking and vitamin D were statistically measured in mean and standard deviation. Qualitative variables like gender and area of living were statistically analyzed in percentage and frequency. ANNOVA was applied to check the significance. $\mathrm{P}$ value $<0.05$ was taken as significant.

Results

Overall, $100 \%(\mathrm{n}=369)$ patients were included, in this study; divided into two groups i.e. non-osteoporosis $60 \%$ $(\mathrm{n}=220)$ and osteoporosis $40 \%(\mathrm{n}=149)$. The mean age, BMI and smoking pack-years of the non-osteoporosis patients was $67.99 \pm 4.61$ years, $23.92 \pm 1.95 \mathrm{~kg} / \mathrm{m}^{2}$ and $41.62 \pm 10.20$ respectively. There were $94.1 \%(\mathrm{n}=207)$ males and 5.9\% $(\mathrm{n}=13)$ females. While, the mean age, BMI and smoking pack-years of the osteoporosis patients was $71.44 \pm 3.90$ years, $21.91 \pm 3.26 \mathrm{~kg} / \mathrm{m}^{2}$ and $49.05 \pm 3.00$ respectively. There were $97.3 \%(\mathrm{n}=145)$ males and $2.7 \%(\mathrm{n}=4)$ females. Education status of the non-osteoporosis patients observed as $36.4 \%(\mathrm{n}=80)$ illiterate and $63.6 \%(n=140)$ elementary or above, while there were $38.3 \%(n=57)$ osteoporosis patients illiterate and $61.7 \%$ $(n=92)$ were elementary or above (Table. 1$)$.

The mean BMD T-score, Systolic BP, Diastolic BP, FVC liters, FVC predicted \%, FEV liters, FEV $_{1}$ predicted $\%$ and $\mathrm{FEV}_{1} / \mathrm{FVC}$ of the non-osteoporosis patients was $-1.54 \pm 0.49,140.41 \pm 12.38 \mathrm{~mm} / \mathrm{Hg}, 84.85 \pm 5.28$ $\mathrm{mm} / \mathrm{Hg}, 2.46 \pm 0.57$ liters, $64.87 \pm 10.82 \%, 1.68 \pm 0.22$ liters, $60.13 \pm 2.68 \%$ and $62.95 \pm 5.74$ respectively. While,

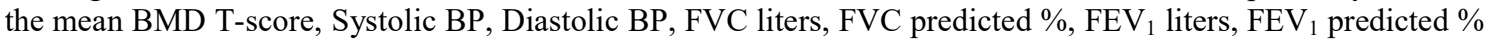
and $\mathrm{FEV}_{1} / \mathrm{FVC}$ of the osteoporosis patients was $-2.79 \pm 0.86,135.99 \pm 8.19 \mathrm{~mm} / \mathrm{Hg}, 78.08 \pm 6.57 \mathrm{~mm} / \mathrm{Hg}$, $1.81 \pm 0.54$ liters, $56.08 \pm 2.34 \%, 1.11 \pm 0.28$ liters, $49.21 \pm 2.94 \%$ and $54.28 \pm 5.19$ respectively. DM was noted as $13.2 \%(n=29)$ and $9.4 \%(n=14)$ for non-osteoporosis and osteoporosis groups respectively. HTN was noted as $62.3 \%(n=137)$ and $43 \%(n=64)$ for non-osteoporosis and osteoporosis groups respectively (Table. 2). The classification of Global initiative for chronic obstructive lung disease GOLD groups (A-D) was shown in table 3.

Significant differences were found between age $(\mathrm{p}=0.000)$, BMI $(\mathrm{p}=0.000)$, smoking pack years $(\mathrm{p}=0.000)$, BMD T-score $(\mathrm{p}=0.000)$, Systolic BP $(\mathrm{p}=0.000)$, Diastolic BP $(\mathrm{p}=0.000)$, FVC, liters $(\mathrm{p}=0.000)$, FVC, predicted $\%,(p=0.000)$, FEV1, liters $(p=0.000)$, FEV1, predicted $\%(p=0.000)$ and FEV1/FVC $(p=0.000)$, in groups. Association was found between HTN $(\mathrm{p}=0.000)$ and GOLD $(\mathrm{p}=0.001)$ in groups. So, HTN and GOLD were the effect modifiers for osteoporosis (Table. 1-2).

Table. 1

Demographic Variables

\begin{tabular}{|c|c|c|c|}
\hline Variable & $\begin{array}{l}\text { Non-osteoporosis } \\
\mathbf{n}=(\mathbf{2 2 0})\end{array}$ & $\begin{array}{l}\text { Osteoporosis } \\
n=(149)\end{array}$ & Test of Sig. \\
\hline Age & $67.99 \pm 4.61$ years & $\begin{array}{l}71.44 \pm 3.90 \\
\text { years }\end{array}$ & $\begin{array}{l}\mathrm{t}=-7.48 \\
\mathrm{p}=\mathbf{0 . 0 0 0}\end{array}$ \\
\hline BMI $^{*}$ & $23.92 \pm 1.95 \mathrm{~kg} / \mathrm{m}^{2}$ & $\begin{array}{l}21.91 \pm 3.26 \\
\mathrm{~kg} / \mathrm{m}^{2}\end{array}$ & $\begin{array}{l}t=7.36 \\
p=0.000\end{array}$ \\
\hline $\begin{array}{l}\text { Smoking } \\
\text { Pack years }\end{array}$ & $41.62 \pm 10.20$ & $49.05 \pm 3.00$ & $\begin{array}{l}t=-8.63 \\
p=0.000\end{array}$ \\
\hline Gender & $\begin{array}{l}\mathrm{M}=94.1 \% \\
\mathrm{~F}=5.9 \%\end{array}$ & $\begin{array}{l}\mathrm{M}=97.3 \%, \\
\mathrm{~F}=2.7 \%\end{array}$ & $\begin{array}{l}\chi^{2}=2.102 \\
p=0.147\end{array}$ \\
\hline $\begin{array}{l}\text { Education } \\
\text { Status }\end{array}$ & $\begin{array}{l}\text { Illiterate }=36.4 \%, \\
\text { literate }=63.6 \%\end{array}$ & $\begin{array}{l}\text { Illiterate }=38.3 \%, \\
\text { literate }=61.7 \%\end{array}$ & $\begin{array}{l}\chi^{2}=0.136 \\
p=0.712\end{array}$ \\
\hline
\end{tabular}

*BMI; Body Mass Index. 
Table. 2

\begin{tabular}{|c|c|c|c|}
\hline Variable & $\begin{array}{l}\text { Non-osteoporosis } \\
\mathbf{n}=(\mathbf{2 2 0})\end{array}$ & $\begin{array}{l}\text { Osteoporosis } \\
n=(149)\end{array}$ & Test of Sig. \\
\hline $\begin{array}{ll}\text { BMD } & \text { T- } \\
\text { score } & \end{array}$ & $-1.54 \pm 0.49$ & $-2.79 \pm 0.86$ & $\begin{array}{l}t=17.69 \\
p=0.000\end{array}$ \\
\hline Systolic BP & $140.41 \pm 12.38$ & $135.99 \pm 8.19$ & $\begin{array}{l}t=3.82 \\
p=0.000\end{array}$ \\
\hline $\begin{array}{l}\text { Diastolic } \\
\text { BP }\end{array}$ & $84.85 \pm 5.28$ & $78.08 \pm 6.57$ & $\begin{array}{l}t=10.92 \\
p=0.000\end{array}$ \\
\hline FVC, liters & $2.46 \pm 0.57$ & $1.81 \pm 0.54$ & $\begin{array}{l}\mathrm{t}=10.93 \\
\mathrm{p}=\mathbf{0 . 0 0 0}\end{array}$ \\
\hline $\begin{array}{l}\text { FVC, } \\
\text { predicted } \%\end{array}$ & $64.87 \pm 10.82$ & $56.08 \pm 2.34$ & $\begin{array}{l}t=9.76 \\
p=0.000\end{array}$ \\
\hline FEV $V_{1}$, liters & $1.68 \pm 0.22$ & $1.11 \pm 0.28$ & $\begin{array}{l}t=21.47 \\
p=0.000\end{array}$ \\
\hline $\begin{array}{l}\text { FEV } 1, \\
\text { predicted } \%\end{array}$ & $60.13 \pm 2.68$ & $49.21 \pm 2.94$ & $\begin{array}{l}t=36.82 \\
p=0.000\end{array}$ \\
\hline FEV $_{1} /$ FVC & $62.95 \pm 5.74$ & $54.28 \pm 5.19$ & $\begin{array}{l}t=14.78 \\
p=0.000\end{array}$ \\
\hline DM ${ }^{*}$ & Yes $=13.2 \%$ & Yes $=9.4 \%$ & $\begin{array}{l}\chi^{2}=1.23 \\
p=0.266\end{array}$ \\
\hline HTN* & Yes $=62.3 \%$ & Yes $=43 \%$ & $\begin{array}{l}\chi^{2}=13.37 \\
p=0.000\end{array}$ \\
\hline
\end{tabular}

* BP, blood pressure; FVC, forced vital capacity; FEV 1 , forced expiratory volume in 1 second; DM, diabetes mellitus; HTN, hypertension

Table. 3

\begin{tabular}{|l|l|l|l|}
\hline \multirow{2}{*}{ GOLD* } & \multicolumn{2}{|l|}{ Groups } & \multirow{2}{*}{ Test of Sig. } \\
\cline { 2 - 3 } & Non-osteoporosis & Osteoporosis & \\
\hline Group A & $(\mathrm{n}=\mathbf{2 6}), \mathbf{1 1 . 8 \%}$ & $(\mathrm{n}=\mathbf{1 1}), \mathbf{7 . 4 \%}$ & $\begin{array}{l}\chi^{2}=15.85 \\
\mathbf{p}=\mathbf{0 . 0 0 1}\end{array}$ \\
\hline Group B & $(\mathrm{n}=\mathbf{1 2 0}), \mathbf{5 4 . 5} \%$ & $(\mathrm{n}=\mathbf{5 7}), \mathbf{3 8 . 3} \%$ & \\
\hline Group C & $(\mathrm{n}=\mathbf{6 0}), \mathbf{2 7 . 3 \%}$ & $(\mathrm{n}=\mathbf{6 4}), \mathbf{4 3 . 0} \%$ & \\
\hline Group D & $(\mathrm{n}=\mathbf{1 4}), \mathbf{6 . 4 \%}$ & $(\mathrm{n}=\mathbf{1 7}), \mathbf{1 1 . 4 \%}$ & \\
\hline Total & $(\mathrm{n}=\mathbf{1 0 0}), \mathbf{1 0 0} \%$ & $(\mathrm{n}=\mathbf{1 0 0}), \mathbf{1 0 0} \%$ & \\
\hline
\end{tabular}

*GOLD, Global Initiative for Chronic Obstructive Lung Disease

Discussion

Results of this study showed two things. One that osteoporosis is common among chronic obstructive pulmonary disease patients. Second risk factors which were significantly associated with development of osteoporosis in COPD. Study showed that $40 \%$ patients of COPD had osteoporosis. Study also concluded that FEV1, body mass index, percentage of diabetes and hypertension were lower in COPD patients who had osteoporosis than patients who had no osteoporosis. Average smoking pack years were higher in osteoporotic group than non-osteoporotic group. Vary similar results were demonstrated by a study done by Chun Wei Lin et al. $\{12\}$. In this study forty percent COPD patients had osteoporosis. Body mass index and FEV1 were significantly associated with development of osteoporosis.

COPD is systemic chronic inflammatory disease. This inflammation in COPD, as demonstrated by oxidative stress, raised red cell distribution width, elevated levels of CRP and pro inflammatory mediators, results in 
protein catabolism $\{13\}$. Study done by Reiko Watanabe et al. in Japan showed that there is significant prevalence of osteoporosis in male COPD patients $\{14\}$. Study done by N.R.Jørgensen et al. showed that $68 \%$ COPD patients had osteoporosis and osteopenia $\{15\}$. A three years follow up study done by LidwienGraatVerboom et al. reported an increase in prevalence of osteoporosis from $47 \%$ to $61 \%\{16\}$.

Smoking also risk factor for developing osteoporosis $\{17\}$. Smoking pack years were higher in osteoporotic group of COPD patients. Smoking cause absorption of bone by lowering $\mathrm{pH}$ of bone salts $\{18\}$. Smoking also induces systemic inflammatory response in the body. Initial point of this inflammation starts from lung which results in production of systemic inflammatory mediators which results in absorption of bone. Study done by $\mathrm{K}$ A Hollenbach et al. concluded that smoking is significantly associated with decrease bone mineral density of hip bone and increase chances of fractures in hip bone $\{19\}$. Result of study done by Chun Hay Ko et al. showed that even passive smoking can cause osteopenia. It effects bone cell differentiation and bone remodeling process $\{20\}$. Study done by Ill PO et al. showed that smoking is modest risk factor for development of osteoporosis $\{21\}$.

Body mass index was lower in osteoporotic group of COPD patients. Result of the study done by Biplob Chowdhury et al. showed that low body mass index predicts osteoporosis $\{22\}$. Study done by Kofi Asomaning et al. showed that women with lower body mass index are at increased risk of developing osteoporosis $\{23\}$. One study done by Terence Ong et al. showed that higher body mass index as in obesity is not protective against fractures $\{24\}$.

Result of this study showed that value of FEV1 was lower in COPD patients who develop osteoporosis. A study conducted in Japan in male COPD patients reported that low FEV1 is independent risk factor of developing osteoporosis $\{14\}$. Another study conducted by Shahid Sheikh et al. in cystic fibrosis patients showed that osteoporosis is common in patients having low FEV1 $\{25\}$.

Higher percentage of diabetic patients were found in osteoporotic group. Study done by Dana Hyassat et al. reported that women with type 2 diabetes mellitus had lower risk of developing osteoporosis $\{25\}$.

So results of this study had shown that osteoporosis is hidden, under considered and very common comorbidity in COPD patients. Many risk factors are involved in developing osteoporosis in COPD patients.

Limitation of the study was that sample size was relatively small and it covered a short geographical area. Study design was also its limitation.

Conclusion

Study concluded that osteoporosis is hidden and common comorbidity in COPD patients. Its prevalence was high among the patients. Significant number of COPD patients had osteoporosis. Pulmonologists should consider and properly investigate osteoporosis in COPD patients.

Conflict of interest

None.

Funding source

None.

References

1- Vanfleteren LE, Spruit MA, Groenen M, Gaffron S, van Empel VP, Bruijnzeel PL, et al. Clusters of comorbidities based on validated objective measurements and systemic inflammation in patients with chronic obstructive pulmonary disease. American Journal of Respiratory and Critical Care medicine. 2013 Apr 1;187(7):728-35.

2- Heidari B. The importance of C-reactive protein and other inflammatory markers in patients with chronic obstructive pulmonary disease. Caspian Journal of Internal Medicine. 2012;3(2):428.

3- Jankowska-Polańska B, Kasprzyk M, Chudiak A, Uchmanowicz I. Effect of disease acceptance on quality of life in patients with chronic obstructive pulmonary disease (COPD). Advances in Respiratory Medicine. 2016;84(1):3-10. 
4- Kitaguchi Y, Yasuo M, Hanaoka M. Comparison of pulmonary function in patients with COPD, asthma-COPD overlap syndrome, and asthma with airflow limitation. International Journal of Chronic Obstructive Pulmonary Disease. 2016;11:991.

5- Sinha T, Nalli SK, Toppo A. A study of clinical profile of patients with chronic obstructive pulmonary disease. International Journal of Community Medicine and Public Health. 2017 Mar 28;4(4):1000-4.

6- Riesco JA, Alcázar B, Trigueros JA, Campuzano A, Pérez J, Lorenzo JL. active smoking and COPD phenotype: distribution and impact on prognostic factors. International Journal of Chronic Obstructive Pulmonary Disease. 2017;12:1989.

7- Walia GK, Vellakkal R, Gupta V. Chronic obstructive pulmonary disease and its non-smoking risk factors in India. COPD: Journal of Chronic Obstructive Pulmonary Disease. 2016 Mar 3;13(2):251-61.

8- Shen TC, Chen WC, Lin CL, Chen CH, Tu CY, Hsia TC, et al. The risk of erectile dysfunction in chronic obstructive pulmonary disease: a population-based cohort study in Taiwan. Medicine. 2015 Apr;94(14).

9- Greenwood C, Clement JG, Dicken AJ, Evans JP, Lyburn ID, Martin RM, et al. The micro-architecture of human cancellous bone from fracture neck of femur patients in relation to the structural integrity and fracture toughness of the tissue. Bone Reports. 2015 Dec 31;3:67-75.

10- Reznikov N, Shahar R, Weiner S. Bone hierarchical structure in three dimensions. Acta Biomaterialia. 2014 Sep 30;10(9):3815-26.

11- Jaramillo JD, Wilson C, Stinson DJ, Lynch DA, Bowler RP, Lutz S, et al. Reduced bone density and vertebral fractures in smokers. Men and COPD patients at increased risk. Annals of the American Thoracic Society. 2015 May;12(5):648-56.

12- Lin CW, Chen YY, Chen YJ, Liang CY, Lin MS, Chen W. Prevalence, risk factors, and health-related quality of life of osteoporosis in patients with COPD at a community hospital in Taiwan. International Journal of Chronic Obstructive Pulmonary Disease. 2015;10:1493.

13- Barreiro E. Protein carbonylation and muscle function in COPD and other conditions. Mass Spectrometry Reviews. 2014 May 1;33(3):219-36.

14- Watanabe R, Tanaka T, Aita K, Hagiya M, Homma T, Yokosuka K, et al. Osteoporosis is highly prevalent in Japanese males with chronic obstructive pulmonary disease and is associated with deteriorated pulmonary function. Journal of Bone and Mineral Metabolism. 2015 Jul 1;33(4):392-400.

15- Jørgensen NR, Schwarz P, Holme I, Henriksen BM, Petersen LJ, Backer V. The prevalence of osteoporosis in patients with chronic obstructive pulmonary disease - a cross sectional study. Respiratory Medicine. 2007 Jan 31;101(1):177-85.

16- Graat-Verboom L, Smeenk FW, van den Borne BE, Spruit MA, Jansen FH, van Enschot JW, et al. Progression of osteoporosis in patients with COPD: a 3-year follow up study. Respiratory Medicine. 2012 Jun 30;106(6):861-70.

17- Curtis EM, Moon RJ, Harvey NC, Cooper C. The impact of fragility fracture and approaches to osteoporosis risk assessment worldwide. Bone. 2017 Jan 22.

18- Daniell HW. Osteoporosis and smoking. Jama. 1972 Jul 31;221(5):509-.

19- Hollenbach KA, Barrett-Connor E, Edelstein SL, Holbrook T. Cigarette smoking and bone mineral density in older men and women. American Journal of Public Health. 1993 Sep;83(9):1265-70.

20- Ko CH, Chan RL, Siu WS, Shum WT, Leung PC, Zhang L, et al. Deteriorating effect on bone metabolism and microstructure by passive cigarette smoking through dual actions on osteoblast and osteoclast. Calcified Tissue International. 2015 May 1;96(5):389-400.

21- Ill PO, Alexandre C. Tobacco as risk factor of osteoporosis, myth or reality?. Revue Du Rhumatisme (Ed. francaise: 1993). 1993 Apr;60(4):280-6.

22- Chowdhury B, Kundu B. Body Mass Index can be a Good Predictor of Bone Mineral Density in Postmenopausal Women in India. International Journal of Public Health Science (IJPHS). 2014 Dec 1;3(4):276-80.

23- . Asomaning K, Bertone-Johnson ER, Nasca PC, Hooven F, Pekow PS. The association between body mass index and osteoporosis in patients referred for a bone mineral density examination. Journal of Women's Health. 2006 Nov 1;15(9):1028-34.

24- Ong T, Sahota O, Tan W, Marshall L. A United Kingdom perspective on the relationship between body mass index (BMI) and bone health: a cross sectional analysis of data from the Nottingham Fracture Liaison Service. Bone. 2014 Feb 28;59:207-10. 
25- Sheikh S, Gemma S, Patel A. Factors associated with low bone mineral density in patients with cystic fibrosis. Journal of Bone and Mineral Metabolism. 2015 Mar 1;33(2):180-5.

26- Hyassat D, Alyan T, Jaddou H, Ajlouni KM. Prevalence and Risk Factors of Osteoporosis Among Jordanian Postmenopausal Women Attending the National Center for Diabetes, Endocrinology and Genetics in Jordan. BioResearch open access. 2017 Jul 1;6(1):85-93. 